\title{
A invenção da Paulistanidade: a emergência de uma cultura histórica, política e escolar/educativa paulista (Século XX)
}

The invention of Paulistanidade: the emergence of a historical, political and school/educational culture in São Paulo (20th century)

La invención de la Paulistanidade: el surgimiento de una cultura histórica, política y escolar/educativa en São Paulo (Siglo XX)

Felipe Tavares de Moraes

Universidade de São Paulo (Brasil)

https://orcid.org/0000-0002-2740-8263

http://lattes.cnpq.br/7447036708299893

felipetavaresmoraes@gmail.com

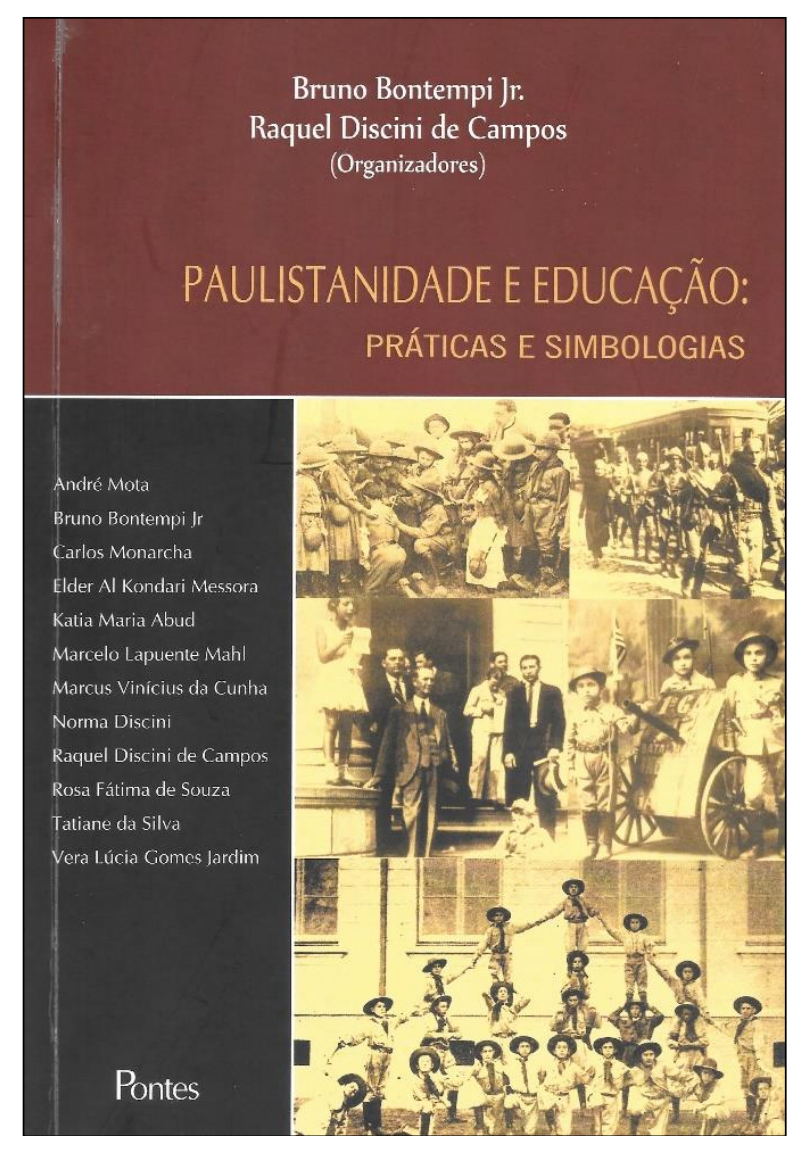

BONTEMPI JR., Bruno; CAMPOS, Raquel Discini de (Org.). Paulistanidade e Educação: práticas e simbologias. Campinas/SP: Pontes Editores, 2018. 333p. 
Vinte e três de maio e nove de julho de 1932 são duas datas importantes na história política de São Paulo. Ambas representam manifestações de descontentamento da elite paulista com os rumos centralizadores que a Aliança Liberal tomara, sob a liderança de Getúlio Vargas, após a chamada "Revolução de 1930". Desferiu-se, a um só tempo, um duro golpe contra a autonomia estadual e a interrupção da hegemonia paulista no governo federal durante a Primeira República (1889-1930). Em 23 de maio, em meio a uma manifestação na Praça da República, que pedia uma nova constituição ao país, houve a repressão de tropas getulistas e foram mortos quatro jovens - Martins, Miragaia, Dráusio e Camargo -, transformados instantaneamente em mártires, cujas iniciais deram nome ao movimento clandestino MMDC. No acirramento dos ânimos políticos, em 9 de julho a elite paulista sublevou-se em armas contra a "tirania” de Getúlio Vargas, ocasionando uma grande mobilização econômica, militar e cultural para o esforço de guerra, vindo a encerrar, com a derrota paulista, em outubro de 1932 (ABREU, 2010; CAPELATO, 1981; HILTON, 1982; SKIDMORE, 1982).

Atualmente, em São Paulo, em 23 de maio é comemorado o Dia do Soldado Constitucionalista; e em 9 de julho, por sua vez, é celebrada a Revolução Constitucionalista. Daquela derrota político-militar ficaram as efemérides cívicas e uma persistente memória e ideologia política, a Paulistanidade, que foi particularmente articulada e mobilizada durante a guerra civil de 1932. Nesse sentido, esta publicação se faz profundamente relevante ao despontar como uma História Social de São Paulo, com importantes apontamentos para a História da Educação Brasileira e competentes contribuições para a História Regional no Brasil. Ressalto, sobretudo, pensar São Paulo do ponto de vista regional, de modo similar aos estudos realizados por Neide Gondim (2007), Durval Muniz Albuquerque Jr. (2009), e Jocelito Zalla e Carla Menegat (2011), que, em relação a formação e consolidação do Estado Nacional Brasileiro, estabeleceram, respectivamente, a invenção da Amazônia, a invenção do Nordeste e a invenção do Gaúcho. Assim, a presente publicação também assinala para a invenção da Paulistanidade.

Paulistanidade e Educação: práticas e simbologias, organizado por Bruno Bontempi Jr. e Raquel Discini de Campos, publicado em 2018 pela Editora Pontes, é uma coletânea que reúne estudos e pesquisas de professores-pesquisadores vinculados, em sua maioria, a universidades estaduais e federais de São Paulo, que buscam problematizar em diferentes objetos e distintas abordagens as dimensões políticas, culturais e educacionais da Paulistanidade. Por sua proficuidade, sofisticação e amplitude, considero que as contribuições realizadas neste volume propõem a emergência de uma cultura histórica (RÜSEN, 2010), política (SIRINELLI; RIOUX, 1998) e escolar/educativa (FARIA FILHO; VIDAL, 2004) paulista nas primeiras décadas do século $\mathrm{XX}$, que envolveram ou evocaram os acontecimentos do Movimento Constitucionalista de 1932 e a ideologia da Paulistanidade.

$\mathrm{Na}$ apresentação do livro, os organizadores apontam que a Paulistanidade consiste em uma ideologia política - erigida no século XVIII, desenvolvida no século XIX e com apogeu até meados do século XX -, que buscou associar as virtudes políticas e culturais do "povo paulista" ao crescimento econômico e demográfico experimentado nas primeiras décadas do século XX; ao passo que também foi um sistema de valores que difundiu nos meios de comunicação, nas instituições da sociedade civil e nos estabelecimentos educativos essa ideologia política, garantindo-lhe adesão e longevidade. Tal ideologia, segundo os organizadores, tomou figurações de ufanismo paulista e de epopeia bandeirante 
ao fixar significados e simbologias que asseguravam a bravura, a ousadia, a coragem e a vitalidade dos naturais de São Paulo; essas imagens procuravam sustentar as aspirações da elite paulista no quadro político nacional, ao mesmo tempo que legitimavam no plano estadual políticas públicas de urbanização, de segurança e de imigração. Outra dimensão da Paulistanidade, evocada pelos organizadores, diz respeito a sua mobilização política no movimento constitucionalista de 1932, no qual a propaganda ideológica articulava presente, passado e futuro: a excepcionalidade dos paulistas conflagrados diante do governo Vargas era derivada da nobreza das famílias bandeirantes e projetava-se para liderar a nação rumo ao progresso e contra as tiranias. Para isso, construiu-se a imagem da locomotiva a puxar vagões vazios representando a potência econômica que, conforme as aspirações da elite paulista, deveria tomar a liderança política e moral do país.

Esta resenha pretende evidenciar as contribuições da coletânea no campo da História da Educação ao colocar em discussão a relação entre cultura, política e educação a partir da ideologia da Paulistanidade. Esta compreendida enquanto manifestação da cultura escolar/educativa, da cultura política e da cultura histórica, e originada na tensão entre região e nação: a identidade nacional foi interpretada em função dos interesses culturais e políticos do regionalismo paulista. Assim, apresento os nove capítulos que compõem a coletânea de maneira temática: cultura histórica, cultura política e cultura escolar/educativa paulista.

Na categoria cultura histórica paulista enquadram-se os capítulos escritos por Katia Maria Abud e Marcelo Lapuente Mahl. O exame da apropriação política da figura do bandeirante para legitimar diferentes projetos políticos foi o trabalho desenvolvido por Katia Abud, referindo-se, notadamente, à elite paulista, em 1932 e do Estado Novo varguista, em 1937 - "O Bandeirante nas disputas políticas do século XX: a utilização do conhecimento histórico" (capítulo 1). Enquanto o movimento de 1932, no confronto com a centralização getulista pela autonomia estadual, transformou o bandeirante em protagonista da revolta paulista, o Estado Novo, por meio da obra de Cassiano Ricardo, notava nas bandeiras um antecedente de governo forte, de caráter popular e eminentemente brasileiro, naturalmente representado no regime autoritário. Deste modo, no intervalo de cinco anos, a autora constatou que os bandeirantes foram de símbolo de São Paulo em luta pelos ideais federalistas, até tornarse símbolo do Estado Novo na imposição de um projeto autoritário e centralizador.

No capítulo 2, "O Instituto Histórico e Geográfico de São Paulo e a ideia de raça (18941940)", Marcelo Mahl analisou o conhecimento histórico produzido pelos sócios do Instituto Histórico e Geográfico do Estado de São Paulo (IHGSP) que defendia uma perspectiva paulista da História do Brasil; ao apropriar-se das teorias raciais vigentes no século XIX, buscou construir a imagem do "tipo racial paulista", derivado da miscigenação de branco com índio, consagrado na figura do bandeirante. Assim, o saber histórico veiculado na revista do IHGSP ficou sintetizado na introdução da primeira revista do instituto, em 1894: "A história de São Paulo é a própria história do Brasil” (p. 55).

Do ponto de vista da cultura política paulista, seleciono os capítulos redigidos por Bruno Bontempi Jr. e André Mota e Elder Messora. No capítulo 3 - "Universidade de São Paulo: a efêmera comunhão das escolas paulistas" - Bruno Bontempi Jr. procurou demonstrar as convergências e as divergências na construção do modelo universitário em São Paulo, a partir da experiência concreta da Universidade de São Paulo (USP). Amplos setores da elite paulista convergiram na construção de um projeto político-cultural baseado na 
Paulistanidade ao propor um modelo universitário: eis o pacto político de fundação da Universidade de São Paulo. Organizado pelo grupo de Julio Mesquita Filho e d'O Estado de São Paulo, o projeto original da Universidade de São Paulo recomendava a integração administrativa e didática do "espírito universitário" sob a liderança da Faculdade de Filosofia, Letras e Ciências, produtora de "ciência desinteressada". Este projeto entrou em colisão com as propostas de ensino superior das faculdades profissionais ajustado ao conhecimento técnico, sob os auspícios da Faculdade Politécnica, acompanhada pela Faculdade de Direito e de Medicina. Portanto, a convergência circunstancial de um projeto universitário paulista viu-se posto a prova diante das divergências dos princípios e os modelos de gestão do poder político-cultural pelos grupos acadêmico-profissionais.

André Mota e Elder Messora, por sua vez, no capítulo 4, "Medicina e Paulistanidade: a luta contra o câncer e os 'cancerosos' nas primeiras décadas do século XX", analisaram o processo de institucionalização da medicina em São Paulo, no qual o tratamento do câncer adquiriu os contornos do discurso da Paulistanidade. Uma vez que o câncer foi considerado uma "doença da civilização", o Estado deveria assumir a vanguarda do seu tratamento como uma questão de saúde pública e destinar instituições médicas para a sua erradicação, com um saber médico específico. Neste contexto, na ausência de mecanismo eficientes de diagnóstico da doença, houve interpretações que vinculavam o câncer ao comportamento sexual principalmente, das mulheres -, bastante marcado pelo moralismo, e, assim, surgia a figura do "canceroso", um estigma social que punia o doente com a repressão moral. Portanto, o tratamento do câncer em São Paulo esteve relacionado ao discurso da Paulistanidade, a construção de instituições e saberes médicos particulares e a organização de uma moralidade repressora à condição do 'canceroso'.

Os capítulos 7 e 8, escritos, respectivamente, por Norma Discini e Raquel Campos e Marcus Vinicius Cunha e Tatiane da Silva, oferecem reflexões entre a cultura história e política paulista. Ao selecionar o conjunto fotográfico publicado no "Revolução de 1932. Fotografia e política" (1982) e o poema "Nossa Bandeira" (1932), de Guilherme de Almeida, Norma Discini e Raquel Campos debruçam-se sobre as manifestações imagéticas e poéticas da Paulistanidade engendradas no contexto do movimento constitucionalista de 1932 "Estética da Paulistanidade: foto e poema no ambiente da Revolução de 1932" (capítulo 7). Tanto o olhar fotográfico quanto o olhar poético elegeram a figura feminina, infantil e adulta, como manifestação heroica e eloquente de apoio aos soldados conflagrados; bem como selecionaram imagens do campo e da cidade, da industria e da lavoura de café como integrantes do orgulho de ser paulista. Tais olhares representaram, em última instância, a estética da Paulistanidade.

Em "Paulistanidade e Persuasão: a paixão por São Paulo na obra de Renato Jardim" (capítulo 8), Marcus Vinicius Cunha e Tatiane da Silva escrutinam o caráter retórico da obra de Renato Jardim dedicadas a abordar a "Revolução de 1930” e a sua relação com São Paulo; nesta obra, Jardim mobilizou argumentos e paixões para criticar Getúlio Vargas e elogiar Washington Luís e São Paulo, ambos os sujeitos julgados do ponto de vista da personalidade e do caráter. Tal qual um promotor público, metáfora utilizada pelos autores, Renato Jardim montou uma peça acusatória e incluiu todos os personagens responsáveis - a imprensa, o exército e a igreja católica - pela "aventura" política que alçou Getúlio Vargas ao comando do país e abarcou também aqueles que foram prejudicados por esse "ato criminoso", o então 
presidente Washington Luís e a cidade de São Paulo - ambos, o homem público honrado e a metrópole civilizada, eram símbolos da Paulistanidade usurpada e tiranizada pelo despotismo getulista. Com essa peça acusatória, Renato Jardim procurava persuadir os seus leitores contra o governo Vargas, ao mesmo tempo que defendia São Paulo como exemplo dos valores da liberdade, da bravura, da liderança e da livre iniciativa.

Carlos Monarcha, Rosa Fátima de Souza e Vera Lúcia Gomes Jardim fecham o livro com os estudos que versam sobre a cultura escolar/educativa paulista. No capítulo 5, "A Face Paulista da Escola Nova (seu espírito, suas condições, seus métodos), Carlos Monarcha apresenta as dimensões da Escola Nova desenvolvida em São Paulo como manifestação do suposto protagonismo bandeirante, observáveis no ensino primário modelar, nas "missões de professores" e na trajetória intelectual de Lourenço Filho. Entre 1910 e 1930, a organização escolar paulista foi considerada modelo para os demais estados da federação, em razão das inovações educativas que incorporavam contribuições da Escola Nova nos métodos de ensino, na administração escolar e na formação de professores. Um desdobramento disso foi a promoção das "missões dos professores paulistas", as quais, em visita aos outros estados brasileiros, competiam auxiliar nos processos de reorganização das escolas normais, na implantação de escolas-modelo e na elaboração de programas de ensino, regulamentos e regimentos. Outra face deste processo foi a trajetória de Lourenço Filho como reformador educacional e teórico da Escola Nova, representando a seleta estirpe de intelectuais paulistas com contribuições exemplares ao conjunto da nação; ficando isso explícito na sua gestão frente a instrução pública do Ceará, e suas obras sobre a Escola Nova e a aplicação de testes de inteligência - ambas baseadas em suas experiências no campo educativo paulista como professor e administrador.

Rosa Fátima de Souza pesquisou a trajetória do escotismo escolar paulista, por meio das finalidades, prescrições e organização das atividades escolares, ressaltando os rituais, os símbolos e as representações que contribuíram na construção do nacionalismo associado ao mito bandeirante e a identidade regional paulista. O escotismo foi introduzido nas escolas paulistas em 1917 e, a partir disso, segundo a autora, passou por três fases: a) entre 1917 e 1920 houve um ensaio da organização do escotismo na rede escolar paulista; b) na gestão de Guilherme Kuhlmann, entre 1921 e 1924, ocorreu a efetivação do escotismo como atividade escolar obrigatória associado a formação cívico-patriótica e aos símbolos da Paulistanidade vinculados a mitologia bandeirante; c) entre as décadas de 1930 e 1970, o escotismo foi considerado uma atividade extracurricular e de caráter facultativo, vindo a desaparecer do currículo escolar paulista. Conforme a autora, nesta segunda fase o escotismo tornou-se uma prática escolar e sua escolarização pautou-se por três aspectos. O primeiro foi a sua organização sob a responsabilidade da Diretoria da Instrução Pública, anteriormente atrelada a Associação Brasileira de Escoteiros. Em seguida, o ensino de escotismo incorporou as tradições paulistas do bandeirismo. Por fim, demarcou-se o acentuado caráter militar na condução das atividades escolares. Durante o seu auge, as Comissões Regionais de Escoteiros deveriam ter uma bandeira e um patrono cujo nome seria um bandeirante. A vinculação entre escotismo e bandeirismo significava oferecer um espaço de cultivo da Paulistanidade no interior das atividades escolares. Estes escritos compõe o capítulo 6 - "Escotismo escolar: moral, civismo e tradições paulistas (1917-1956)". 
Vera Jardim investigou as propostas dos intelectuais para o ensino de música nas escolas paulistas, recortando especificamente a atuação do maestro João Gomes Junior entre 1893, quando foi catedrático de música na Escola Modelo do Carmo, e 1930, ao assumir o cargo de Inspetor Geral de Música das escolas do Estado de São Paulo - "A Estética Musical Escola Paulista e os Métodos de João Gomes Junior”, capítulo 9. A autora privilegia em sua exposição, no interior da extensa atuação profissional de João Gomes Junior, a produção de manuais escolares e a sua indicação oficial para compor o material didático obrigatório no ensino público paulista - principalmente, Curso Theorico e Prático de Música Elementar (1903). A obra musical de João Gomes Junior contribuiu para consolidar as instituições educativas relacionadas a educação musical ao publicar seus manuais escolares e formular prescrições e normas oficiais na legislação educativa. A seleção de métodos e repertórios musicais baseavam-se na cultura musical europeia e nos valores moralizadores dos republicanos paulistas, ao passo que também estimavam a Paulistanidade, presente na partitura musical Ser Paulista, composta no inconfundível ano de 1932, com letra de Carmem Lia.

À guisa de conclusão reafirmo que a coletânea apresenta valiosa contribuição aos estudiosos da História Social de São Paulo e, particularmente, a História da Educação Brasileira. No campo educativo, a publicação reúne pesquisas que trabalham com um conceito ampliado de educação, que não se restringe ao território escolar, ao debater criticamente a relação entre cultura, política e educação na sociedade civil. Por isso, observo neste livro a emergência, pelas potencialidades heurísticas do objeto Paulistanidade, de uma cultura histórica, política e escolar/educativa paulista. Por fim, de fato, não é possível entender a construção da nacionalidade brasileira sem as contribuições da invenção da Paulistanidade.

\section{Referências}

ABREU, Marcelo Santos de. Os Mártires da Causa Paulista: culto aos mortos e usos políticos da Revolução Constitucionalista de 1932 (1932-1957). 2010. 312f. Tese (Doutorado em História Social). Universidade Federal do Rio de Janeiro - Rio de Janeiro.

ALBUQUERQUE JR., Durval Muniz de. A invenção do Nordeste e outras artes. $4^{\mathrm{a}}$ ed. Recife: FJN; Ed. Massangana; São Paulo: Cortez, 2009.

CAPELATO, Maria Helena. O movimento de 1932: a causa paulista. São Paulo: Brasiliense, 1981.

FARIA FILHO, Luciano Mendes; VIDAL, Diana Gonçalves. A cultura escolar como categoria de análise e como campo de investigação na história da educação brasileira. Educação e Pesquisa, São Paulo, v.30, n.1, p.139-159, jan./abr. 2004. https://doi.org/10.1590/S1517-97022004000100008

HILTON, Stanley. A guerra civil brasileira: história da Revolução Constitucionalista de 1932. Rio de Janeiro: Nova Fronteira, 1982.

NEIDE, Gondim. A invenção da Amazônia. $2^{\circ}$ ed. Manaus: Editora Valer, 2007. 
RÜSEN, Jörn. A razão histórica: teoria da História - os fundamentos da ciência histórica (v.1). Brasília: Editora da UnB, 2010.

SIRINELLI, Jean-François; RIOUX, Jean-Pierre (Orgs.). Para uma história cultural. Tradução de Ana Moura. Lisboa: Estampa, 1998.

SKIDMORE, Thomas. Brasil: de Getúlio a Castelo. Rio de Janeiro: Paz e Terra, 1982.

ZALLA, Jocelito; MENEGAT, Carla. História e memória da Revolução Farroupilha: breve genealogia do mito. Revista Brasileira de História da Educação, v.31, n.62, p.49-70. 2011. https://doi.org/10.1590/S0102-01882011000200005 